\title{
Nasal Endoscopic Findings in Allergic Rhinitis: A Prospective Study
}

\author{
Dr Sujeet Kumar ${ }^{1}$. Dr Ramanuj Singh ${ }^{2}$ Dr Manish Kr Singh ${ }^{3}$ Dr Subrata.Nag ${ }^{4}$ \\ Assistant.professor,Dept.of.ENT ${ }^{l}$.Assistant.professor,Dept.of.Anatomy ${ }^{2}$.Assistant.professor,Dept.of General \\ surgery ${ }^{3}$.Professor of Anesthesia ${ }^{4}$. Narayan Medical College \& Hospital.Jamuhar.Sasaram.Bihar
}

\begin{abstract}
:
Introduction: About $1 / 5^{\text {th }}$ of the world population is affected by allergic rhinitis, affecting to quality of life, require a systemic approach of history, examination, investigation and sometime special allergic testing. Objective of this study is to evaluate the nasal endoscopic findings in the patients of allergic rhinitis.

Material and Method: This study consists of 58 patients of Allergic Rhinitis in whom nasal endoscopic examination was done. All the patients had nasal symptoms; rhinorrhoea(100\%), nasal obstruction (87.96\%), sneezing(81.03), itching of the palate(41.38\%), fullness of the ears(37.93\%), headache(29.31\%). In all patients nasal endoscopic examinations were done under local anesthesia except in children.

Result: Nasal endoscopic findings were as follows : DNS(72.41\%), inferior turbinate hypertrophy $(55.17 \%)$, watery discharge on nasal floor (41.38\%), septal spur (27.59\%), polypoidal anteriore end of middle turbinate and blocked maxillary ostia were found in $24.14 \%$ each, abnormal ethmoidal bullae (13.79), enlarged aggar nasi cells (27.59\%), mucopurulent discharge in maxillary ostia (22.41\%). Concha bullosa and medially bent uncinate process were found in $(09.09 \%)$ each , paradoxical bent middle turbinate $(03.44 \%)$ and polyp in sphenoethmoidal recess $(09.09 \%)$ of cases. .

Conclusion: Nasal endoscopic work up is an effective diagnostic tool. It is particularly useful for the delineation of the structures in the region of middle meatus distinguishing the middle turbinate from other soft tissue. It can also be used for taking nasal tissue for biopsy.
\end{abstract}

Key words: Nose, Endoscopy, Allergic Rhinitis

\section{Introduction}

At least $20 \%$ of the patients seen in the ENT out door have complaints related to allergic rhinitis is most common of them(1). clinical diagnosis in a condition where the symptoms may vary from mild stuffy nose to severe disability. Other symptoms like watery nasal discharge ,recurrent sneezing, itching in nose ,ear, throat ,eye and fullness in ear. In describing allergic rhinitis alone, the nasal membrane range from gray to pale-blue ,blue gray ,pink ,purple blanching, normal wet, swollen, moist, chapped white, glistening etc(2) .Sinus endoscopy, to peep in side the maxillary sinus and provides information which is superior to that obtained by the any other investigations(3,4). Nasal endoscopy and antroscopy can conveniently be performed as an out patient procedure under L.A(4). Nasal endoscopy provides accurate assessment of both disease and anatomical variations and during surgery, allows a very clear and well illuminated field.Nasal endoscopy and endoscopic sinus surgery aim effectively for early diagnosis and to provide drainage and ventilation to the PNS and hence radical procedures on the PNS can be avoided(4). Objective of this study was to find out the endoscopic pathology in allergic rhinitis.

\section{Materials And Method}

This prospective study was carried out in the ENT department of Narayan Medical college and hospital, Jamuhar, Sasaram since $2^{\text {nd }}$ March 2012 to $30^{\text {th }}$ April 2014. 58 clinically diagnosed cases of Allergic Rhinitis of all age groups and both the sexes were selected for this study .Only those Patients who had symptomatology consisting of some or many of the following symptoms - paroxysmal sneezing, Running or stuffy nose, Watery eyes, Palatal itching or itching of the nose, post nasal drip, headache. history of allergy like asthma, urticaria, food sensitivity, drug reaction, lacrimation, conjunctivitis, recurrent nasal discharge either perennial or seasonal, family history of allergy and who had not received the antihistamines and steroids therapy, either locally or systemically before 15 days, were selected .Complete nose, ear and throat examination was performed in every cases and findings were noted. In nasal examination stress was given on rhinoscopic findings. Nasal endoscopy was done in all cases and recorded in case record form. Before the nasal Endoscopic examination, $2 \%$ xylocaine with adrenaline socked in 3 pieces of cotton were applied in the Floor of Nasal Cavity,Middle meatus and Root of Nasal Cavity.General anesthesia was preferred in children, apprehensive and 
un-co-operative patients and in cases of extensive pathology. $30^{\circ}$ angled nasal endoscope was used for the studies of nasal pathology.

Position of Endoscopist:- The surgeon was stand on patient right. The patient was in supine position with the head facing the examiner.

Diagnostic nasal endoscopy was done in three passess.

First pass:- The endoscope was passed along the floor of nose, inspecting inferior turbinate, septum. Once choana was traced the eustachian tube orifice, fossa of Rossenmuller and nasopharynx were seen. While the scope was withdrawn it was insinuated under the inferior turbinate to examine the inferior meatus. In some cases the nasolacrymal duct opening could be visualized

Second pass:- When gone posteriorly lateral to superior turbinate to identify sphenoidal ostium in sphenoethmoidal recess.

Third pass:- It was done along middle meatus. The free edge of uncinate process, the posterior fontanelle and accessory ostium were seen. Other structures seen were bulla ethmoidalis, frontal recess, hiatus semilunaris.

\section{Result And Observation}

The present study is based on observation of 58 patients suffering from allergic rhinitis. The observations were based on the history, physical finding and the evaluation of allergy was done by clinical examination and nasal endoscopy and some investigative procedure. Age distribution of the cases The least number of cases fell in the age group above 50 years and the maximum number of cases fell in the age group of $21-35$ years. The younger patient registered was aged 8 years while the oldest patient registered was aged 60 years. Sex ratio Amongst the patients studied $63.79 \%$ were Male and $36.21 \%$ were Female. The ratio of male to female was $1.76: 1$.

Table - 1 Frequency of Endoscopic Pass I finding in Allergic Rhinitis

\begin{tabular}{|l|l|l|l|l|}
\hline S1.No. & Finding & No. of cases & Total & $\%$ \\
\hline 1. & DNS & 42 & 58 & 72.41 \\
\hline 2. & Inf. turbinate hypertrophy & 32 & 58 & 55.17 \\
\hline 3. & Watery discharge on floor & 24 & 58 & 41.38 \\
\hline 4. & Mucopurulent discharge on inf. turbinate & 3 & 58 & 5.17 \\
\hline 5. & Pus in inf. turbinate & 3 & 58 & 5.17 \\
\hline 6. & Septal spur & 16 & 58 & 27.59 \\
\hline
\end{tabular}

Table - 2 Frequency of Endoscopic Pass II findings in Allergic Rhinitis

\begin{tabular}{|l|l|l|l|l|}
\hline Sl.No. & Frequency & No. of cases & Total & $\%$ \\
\hline 1. & Mucopurulent collection in sphemoethimoidal region & 1 & 58 & 1.72 \\
\hline 2. & Watery discharge in sphenoethmoidal region & 10 & 58 & 17.24 \\
\hline 3. & Polyp in sphenoethmoidal space & 3 & 58 & 9.09 \\
\hline 4. & No positive findings & 44 & 58 & 75.86 \\
\hline
\end{tabular}

Table - 3 Frequency of Endoscopic Pass III findings in Allergic Rhinitis

\begin{tabular}{|l|l|l|l|l|}
\hline Sl.No. & Finding & No. of cases & Total & $\%$ \\
\hline 1. & Swollen oedematous Aggar nasi cells & 16 & 58 & 27.59 \\
\hline 2. & Polypoidal anterior end of middle turbinate & 14 & 58 & 24.14 \\
\hline 3. & $\begin{array}{l}\text { Oedema and polypoidal mucosa at the attachment of ant. end } \\
\text { of middle turbinate }\end{array}$ & 15 & 58 & 25.86 \\
\hline 4. & Oedematosus and polypoidal Uncinate process & 11 & 58 & 18.96 \\
\hline 5. & Polyps from frontal recess & 4 & 58 & 6.99 \\
\hline 6. & Polyps from ant. ethimoidal region & 8 & 58 & 13.79 \\
\hline 7. & Polyps from maxillary ostia & 6 & 58 & 10.34 \\
\hline 8. & Mucopurulent discharge in maxiallary meatus & 13 & 58 & 22.41 \\
\hline 9. & Oedema and polypoidal at mucosa in infindibulurn & 10 & 58 & 17.24 \\
\hline 10. & Blocked Maxillary ostia & 14 & 58 & 24.14 \\
\hline 11. & Stenosis of maxillary ostia & 6 & 58 & 10.34 \\
\hline 12. & Accessory maxillary ostia & 9 & 58 & 15.52 \\
\hline 13. & Oedematous ethimoidal bulla & 4 & 58 & 6.99 \\
\hline
\end{tabular}

Table - 4 Frequency of Anatomical variation in OSTEO-_MEATAL -COPLEX area by Endoscopic examination in patient of Allergic Rhinitis

\begin{tabular}{|l|l|l|l|l|}
\hline Sl.No. & Frequency & No. of cases & Total & $\%$ \\
\hline 1. & Concha bullosa & 3 & 58 & 9.09 \\
\hline 2. & Paradoxical bent middle turbinate & 2 & 58 & 3.44 \\
\hline
\end{tabular}




\begin{tabular}{|l|l|l|l|l|}
\hline 3. & Medially bent uncinate process & 3 & 58 & 9.09 \\
\hline
\end{tabular}

\section{Nasal Endoscopic Picture In Different Passes}

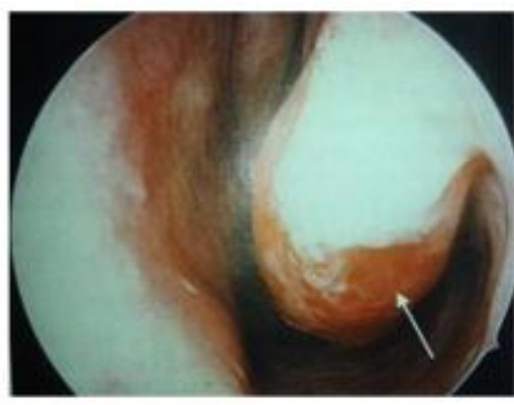

Fig- 1: Left side Inferior turbinate hypertrophy.

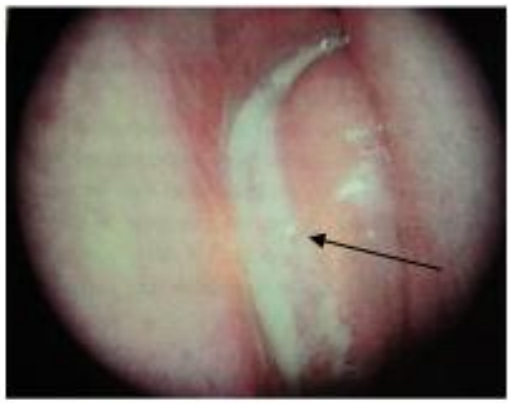

Fig-2: Mucopurulent discharge in middle meatus.

\section{The mucosa is edematous, with obliteration of \\ The space between the middle turbinate and latera nasal wall.}

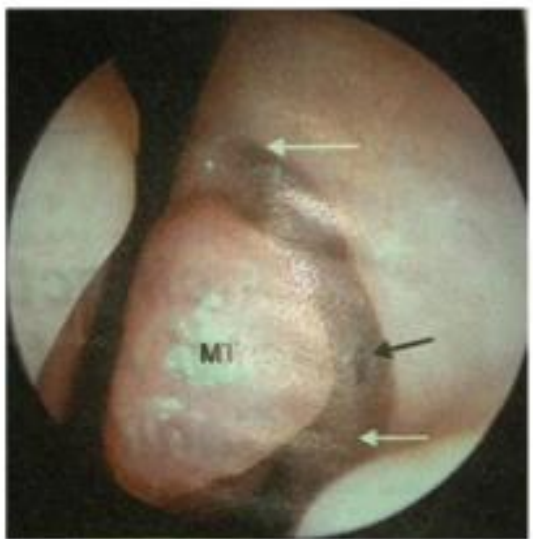

Fig-4.MT -means hypertrophied middle

turb in ate (Concha bullosa)\& perforation

of uncinate (black arrow) is seen. The medially

Bent middle portion of Uncinate process lies

Between the two white arrows.

\section{Discussion}

In our study most of the patients of allergic rhinitis (79.31\%) were between 11 years to 35 years of age. Only $5.17 \%$ or the people above the age of 50 years and $6.90 \%$ below the age of 10 years were found to suffer from the disease. Allergic rhinitis was found to have a predilection for males who outnumbered the females by a ratio of 1.76:1. Allergic rhinitis had a tendency to burn itself out over the lapse of time. Diagnostic nasal endoscopy was preferably performed with a $30^{\circ}$ wide angled nasal endoscope. It had enough direct forward vision and enables good visualization of Middle meatus and also had panoramic vision of nasopharynx. Routine nasal endoscopy need not be part of the evaluation of all patients with nasal sinus disorders but is particularly valuable in confirming diagnoses, particularly in patients where anterior rhinoscopy is limited by anatomic obstruction (5,6 ). Nasal endoscopy may reveal signs predictive for Allergic Rhinitis diagnosis in children. Inferior and middle turbinate contact were reliable predictive factors for AR whereas pale turbinate did not predict it (7). 
In our study deviated nasal septum and interior turbinate hypertrophy were the most common findings on pass I nasal endoscopic examination. In pass II nasal endoscopic examination 75.86\%. Patients had no findings, watery discharge in sphenoethmoidal region in $17.24 \%, 9.09 \%$ had polyp in sphenoethmoid space and $1.75 \%$ had mucopurulent collection in spheno-ethmoid space.On endoscopic findings in pass III. Blocked maxillary ostia, stenosis of maxillary ostia and accessory maxillary ostia were found in $24.14 \%, 10.34 \%$ and $15.52 \%$ cases respectively.Oedemeatous and polypoidal unicinate process were found in $18.96 \%$ cases.

$24.14 \%$ cases each had polypoidal anterior end of middle turbinate and oedema with polypoidal mucosa at the attachment of anterior end of middle turbinate was found in $25.86 \%$ cases. Swollen oedema aggar nasi cells in $27.59 \%$ of cases. $13.79 \%$ cases had polyp in anterior ethmoidal region. $10.34 \%$ cases had polyp from maxillary ostia and $6.99 \%$ cases had polyp coming out from frontal recess. Oedema and polypoidal mucosa in infundibulum was found in $17.24 \%$ cases. Mucopurulent discharge in middle meatus was found in $22.41 \%$ cases.In endoscopic examination concha bullosa, paradoxical bent middle turbinate and medially bent uncinate process were found in $9.09 \%, 3.44 \%$ and $9.09 \%$ cases respectively. These findings suggested that variations in endonasal was not by itself a pathology or a cause of symptoms. However, a combination of these variations may narrow the cleft of the osteo- meatal unit and cause stenosis of these areas which pre-disposes patients to persistent symptoms.

\section{Conclussion:}

Nasal endoscopic work up is an effective diagnostic tool. It is particularly useful for the delineation of the structures in the region of middle meatus distinguishing the middle turbinate from other soft tissue. It can also be used for taking nasal tissue for biopsy.

\section{References}

[1]. Gutman, Michael., Augusto Torres, Kevin J. Keen et al. Prevalence of allergy in patients with chronic rhino sinusitis. Otolaryngology- Head and Neck Surgery. 2004;130(5): 545-552.

[2]. Hansel FK. Clinical allergy. St. Louis, The C.V. Mosby co.1953; 654-659, 779-790.

[3]. James A. Stankiewicz and James M. Chow. Nasal endoscopy and the definition and diagnosis of chronic rhinosinusitis. Otolaryngology - Head and Neck Surgery. 2002; 126 (6): 623-627.

[4]. Gupta SC. Sachin Jain, et al Antroscopic and cytological Study of the maxillary sinus mucosa in allergic rhinitis.2004; 2(4):

[5]. Jareoncharsi P. Thitadilok V. et al . Nasal endoscopic findings in patients with perennial allergic rhinitis. Asian Pacific Journal of Allergy \& Immunology. 1999; 17(4): 261-7.

[6]. Benninger, Michael S. Nasal endoscopy; Its role in office diagnosis. American Journal of Rhinology. 1997; 11(2):177-180(4).

[7]. Ameli F, Brocchetti F. et al. Nasal endoscopy in children with suspected allergic rhinitis. Laryngoscope.2011; 121(10): 2055-9 